\title{
Older people's social sharing practices in YouTube through an ethnographical lens
}

\author{
Sergio Sayago* \\ Interactive Technologies Group \\ Universitat Pompeu Fabra \\ sergio.sayago@upf.edu
}

\author{
Paula Forbes \\ Dept of Computer Science \\ University of Aberdeen \\ paula.forbes@abdn.ac.uk
}

\author{
Josep Blat \\ Interactive Technologies Group \\ Universitat Pompeu Fabra \\ josep.blat@upf.edu
}

\begin{abstract}
This paper reports on a classical, face-to-face ethnographical study of YouTube use and social sharing practices by 32 older people (65-90). The study was conducted in a computer clubhouse in Scotland over an 18-month period. Whereas research on Social Network Sites (SNS) is on the rise, very little is known about how people aged 60+ use them in their everyday lives, despite an ageing population. The study shows that the use of YouTube by this group of older people is occasional and motivated by face-to-face or online conversations in e-mails. They watch videos that they find meaningful, do not upload videos because they do not perceive any benefit in it, and search for videos by writing sentences, instead of clicking on categories, to reduce cognitive load. Online comments in YouTube are seldom read nor made. Instead, they make comments in f2f, and/or emails, always with key members of their social circles. They rate videos in these online and offline conversations, and share videos by capitalizing on previously learned strategies, such as copyand-paste. We argue that these results provide a more complete picture of SNS and older people than that given by previous studies, and enable a discussion on their User Experience. We also discuss some implications for design.
\end{abstract}

Social Network Sites. YouTube. Older people. Ethnography. User Experience.

\section{INTRODUCTION}

The rising popularity of Social Network Sites (SNS) has made them the object of an ever-increasing number of research studies. Yet, very little research has considered, or has been conducted with older people $(60+)$, despite a growing ageing population. Thus, examining their social sharing practices to improve their interactions with SNS is timely and important.

In this paper, we discuss the everyday use of YouTube by 32 people, aged $65-90$, with mild-tomoderate age-related changes in functional abilities. We address their motivations, videocontent consumption and searching strategies, privacy and interaction issues, and how they conduct key social sharing practices (i.e. rating, commenting, recommending and sharing) in this $\mathrm{SNS}^{1}$. We draw on an ethnographical study of ICT use, which adopted a classical, long-term face-to-

\footnotetext{
* This research was conducted while being a visiting post-doc (Beatriu de Pinós Fellowship) in the School of Computing at the University of Dundee (Dundee, Scotland)

1 “(...) websites focused on media sharing began implementing SNS features and becoming SNSs themselves. Examples include Flickr (...), Last.FM (...), and YouTube" (Boyd and Ellison, 2008: 216).
}

face approach, conducted in a computer clubhouse in Scotland during 18 months. We outline key results of our study next.

Our participants' use of YouTube is not influenced by how popular (i.e. number of likes and dislikes) a video or a comment is, but mostly driven by their own needs and interests, as summarised in this exemplary comment, "I have my own likes and dislikes". Face-to-face conversations and e-mails within their social circles are how they rate, comment, recommend and share videos, rather than, for instance, clicking on 'thumbs up or down', "My son will like this video, I'm going to my gmail to send him an e-mail about it".

The rest of the paper is organised as follows. In 2 , we examine previous work related to this paper. In 3 , we describe the ethnographical study, and present the results in 4 and 5 . We discuss in 6 the findings, methodology and implications. In 7, we present the main conclusions, and summarise ongoing and future work. 


\section{RELATED WORK}

We discuss and review previous SNS studies in $\mathrm{HCl}$ research with older people in 2.1 , and studies addressing key topics in SNS research in 2.2.

\subsection{SNS in $\mathrm{HCl}$ research with older people}

We conducted a keyword-based search in large databases and academic search engines ${ }^{2}$ to identify previous SNS studies in $\mathrm{HCl}$ research with older people. Our search yielded few papers, which we review and discuss next.

Concerns about social behavior and privacy in SNS are highlighted in (Lehtinen et al, 2009) and (Gibson et al, 2010). The former explored how a group of 8 older people with no previous experience with SNS understood them. This group used Netlog - a SNS in Finnish, over 4 weeks, and the main finding of the interviews conducted before and after using it was that they regarded "the internet as a dangerous place, and SNS as places of socially unacceptable behavior" (Lehtinen et al, 2009: 45). This result resonates with (Gibson et al, 2010), who explored the perceptions of 17 older people, who were active Internet users, towards MyFriendsOnline and FaceBook. Discussions in two focus groups revealed, for instance, that they were anxious to retain their privacy and afraid of identity theft.

By contrast, (Harley and Fitzpatrick, 2009), (Ryu, Kim and Lee, 2009) and (Pfeil, Arjan and Zaphiris, 2009) present a much less negative picture. Harley and Fitzpatrick (2009) conducted a multimodal interaction analysis of four videos exchanged between an 80-year-old video blogger and three of his younger viewers, showing that YouTube can facilitate a conversational context in which common ground is shared, and intergenerational communication can occur. Factors affecting older people's participation in video user-created content (UCC) was the focus of (Ryu, Kim and Lee, 2009), and the online survey they conducted with 290 Korean people aged $50+$ showed that "older people are not highly resistant to change and will adopt video UCC", contrary to stereotypes, "if some conditions are satisfied" (Ryu, Kim and Lee, 2009: 627), such as perceived benefit, ease of participation and enjoyment, elements of the Technology Acceptance Model (TAM) (Venkatesh et al, 2003). Age differences and similarities in the use of MySpace were addressed in (Pfeil, Arjan and Zaphiris, 2009) by crawling MySpace's user profile pages, finding, amongst other results, that

\footnotetext{
${ }^{2}$ Keywords $=$ (older people, older adults, senior, elder, YouTube, Facebook, Twitter, Social Network Sites). Databases = SCOPUS, ACM DL, Elsevier, SpringerLink, SAGE, Taylor \& Francis. Academic search engines: Google Scholar, Microsoft Academic Search.
}

older people's networks of friends tend to have a more diverse age distribution than those of teenagers.

These different and even contradictory results might be accounted for the heterogeneity of older people as SNS (non) users. However, we consider this suggests that more research is needed. Our study addresses most of the issues raised by the studies reviewed before, it is based on a long-term period of in situ observations and conversations, and covers other topics, e.g. social sharing practices and everyday use, which are relevant in SNS research (see 2.2).

\subsection{Some key topics of research on SNS use}

There is growing interest in SNS research to understand how people use SNS and conduct social sharing practices. We review and discuss next recent and highly cited studies, which we consider exemplary of the growing attention towards these topics and of how SNS research is addressing them.

Commenting and associated ratings might help us understand better community interests, and (Siersdorfer et al, 2010) looked into how useful comments on YouTube are by adopting a data mining approach, with a test collection of 6 million comments on 67,000 YouTube videos. The results revealed that "community tends to cast more positive than negative votes in comments", and that "most comments $(50 \%)$ lack votes" (Siersdorfer et al, 2010: 89), which seems to be a time-persistent issue, as a previous study, adopting a similar approach, showed (Cha et al, 2007:3), "While 54\% of all videos are rated, the aggregate ratings only account for $0.22 \%$ of the total views. Comments, a more active form of participation, account for mere $0.16 \%$ of total views". The private and public dichotomy of YouTube has also attracted research. An ethnographical investigation into young people's engagement with online video sharing on this SNS, based on 54 semi-structured interviews and observations carried out over a one-year period, pointed out that whereas YouTube is a public space, the participants of this study developed their own strategies for their privacy, such as "using your username as the tag of the video makes it impossible for people who do not know you to find your videos" (Lange, 2008: 367). By crawling 10 million profiles in Facebook, (Wilson et al, 2009) showed that real interactions in it happen with very few people, and (Poblete et al, 2011), by analysing over 5 billion tweets over 1 year, discussed, amongst other aspects, similarities and differences in the content of tweets in 10 countries, finding that within the US Twitter is mostly used for formal news dissemination, whereas in Japan, South 
Korea and Brazil, the use of Twitter is more for conversation.

Despite the interesting findings, most of them based on very large samples of data, none of the studies reviewed above considered people aged $60+$ in their analyses. We focused on them in our study, which we present next.

\section{ETHNOGRAPHICAL STUDY}

Ethnography in SNS research is encouraged in the highly cited Boyd and Ellison (2008: 224) "Richer, ethnographic research on populations more difficult to access (including non-users) would further aid scholars' ability to understand the long-term implications of these tools". Ethnography has also been conducted in SNS studies with young and adult people, notably by Boyd (see Boyd and Ellison, 2008: 224) - and also (Lange, 2008), reviewed in 2.2. Still, none of the papers in 2.1 adopted a classical approach (Fetterman, 2010), i.e. combining in situ observations and conversations during extended periods of time, and very few studies in $\mathrm{HCl}$ with older people have conducted classical ethnography either (Sayago and Blat, 2010).

We describe next our classical ethnographical study, which helped us improve our understanding of older people's SNS use, as we discuss further in 6.

\subsection{Context, participants and equipment}

We conducted our study in the Dundee User Centre (DUC), a drop-in clubhouse physically situated within, and run by, the School of Computing at the University of Dundee. Since 2005, the DUC aims to help older people learn about and use ICT at their own pace, and also encourage them to partake in ICT accessibility research activities [11]. The DUC runs 4, 2-hour free drop-in sessions a week, every weekday morning except Monday, from 10 to $12 \mathrm{~h}$.

32 DUC participants (25 aged $65-75 ; 7,76-90$ ) took part in our study. They are original from Scotland or England. Around $50 \%$ of them finished their education when they were 15-18 years old, and had no previous contact with computers before joining the DUC. The rest hold a university or college degree and had used computers in their jobs. This sample is a mix of 'beginners' and longterm ICT users, encompassing two important profiles of older people for $\mathrm{HCl}$ research, and the age range of its members corresponds to the two biggest cohorts $(65-75,76-90)$ of the current and projected (2020-2060) older population in Europe ${ }^{3}$.

Sony VAIO laptops with Microsoft Windows Vista and XP operating systems, and Apple iMacs were available at the DUC, and were used by the participants throughout the study.

\subsection{Research methods}

From September 2010 to February 2012, we met the DUC participants up to four times per week, 2 hours each time. This resulted in over 500 hours of in situ observations and informal conversations ${ }^{4}$.

We also conducted 23 semi-structured interviews (9 pair-based, 14 individual) at the DUC to better understand our observations ${ }^{5}$. At the end of the interviews, we read out our notes and asked the participants to agree with or add information to them.

We took our fieldnotes (observations, informal conversations and interviews) by using paper and pencil, as doing so was a common practice amongst the DUC participants. We consider that other technologies, often used in ethnography, e.g. video cameras, could have been far more intrusive in this setting.

\subsection{Data analysis}

We analysed the fieldnotes while we were gathering them. We did so by conducting open, axial and selective coding, and the constant comparative technique of the Grounded Theory approach for ethnographical qualitative analysis (Charmaz and Mitchell, 2007) every two months ${ }^{6}$.

We first read all the notes gathered so far (i.e. at month 2, 4 and so on) to gain an overall sense of the data. We then created a list of codes that reflected 'what was going on' in our notes. After a second reading, we refined the list by, for instance, deleting some codes and creating new ones. A third list resulted from grouping the codes into main and sub-categories. We repeated this procedure until no new categories were found.

\footnotetext{
${ }^{3}$ At the time of writing this article, in Eurostat, Europe's latest set of population projection was exercise EUROPOP2010: http://tinyurl.com/d9c9p55

${ }^{4} 17$ participants attended almost all the sessions, while the rest attended one or two weekly, due to other commitments, such as regular medical check-ups, holiday trips \& babysitting.

${ }^{5} 10$ interviews focused on their ICT learning, and 12 on their ICT use and attitudes towards key research areas, such as SNS.

${ }^{6}$ Same analytical window used in a 3-year ethnographical study (Sayago and Blat, 2010).
} 
This procedure led to the following list of main and sub-categories, which we use to discuss the results in 4 and 5:

(i) Everyday use: occasional, motivations, social circles, video consumption, privacy and perception of usefulness, meaningful use, searching strategies, cognition

(ii) Social sharing practices: comments and ratings in e-mails and face-to-face conversations, popularity rankings are ignored, YouTube comments are not read, learned strategies for sharing, cognition

\section{EVERYDAY USE}

\subsection{Occasional use, motivated by face-to-face or online conversations}

Our observations and conversations indicated that most of the participants (27) used YouTube occasionally, once or twice a fortnight, and watched 1 or 2 videos each time. Only 5 participants, who attended the DUC regularly, used YouTube 2-3 times a week, 30-40 minutes each time ${ }^{7}$. E-mails sent by close friends encouraged our participants to use YouTube, "I watch the videos that a friend of mine in Australia sends me in e-mails as links", as well as face-to-face conversations with other participants, as illustrated in the following real-life scenario. While a participant was drinking a cup of coffee, and discussing his activities with the computer, mainly new discoveries he had made, with another participant and the main author, he made the following comment: "Last Friday, J. told me to look at the YouTube video of the airline company breaking guitars, you were here, weren't you? It was terrific!" Motivation is an important part of the model of user experience proposed by Hassenzahl (2010: 44), mostly addressed in the element "why? - be goals (activity - motives)", and of the concept of flow in YouTube suggested by (Burguess and Green, 2011), where it is argued that not only should we look at what happens within it, as most of the studies have done so far, but also out of it. We discuss in 6 the importance of addressing motivations and flow(s) to improve older people's experiences with YouTube.

\subsection{Video consumption instead of generation}

All our participants knew that they could upload videos to YouTube, as we either showed them the steps to do so or talked to them about it, but none

\footnotetext{
7 These participants also reported using YouTube at home. Indeed, we helped two of them to set YouTube as one of the starting pages of the web browser (Google Chrome) they used to go online in their laptops.
}

of them did so or were interested in uploading their videos.

They expressed privacy concerns about their videos $^{8}$. For instance, while a participant was showing us (the main author) a number of videos related to the wedding of her daughter that she has in her laptop, she reported that "I don't want other people to see my videos, they're personal, of weddings and birthdays". This opinion resonates with those gathered in the focus groups of (Gibson et al, 2010), reviewed in 2, and contradicts (Kwasny et al, 2008), who, in focus groups too, found that older people tended to define privacy in terms of space (e.g. rooms, house), instead of information.

Our participants also reported a perceived lack of usefulness, "I guess I could upload them and create this sort of channel, as she [second author] has shown me before, but it's too much bother, you know, I only use YouTube for watching (...) and I do it occasionally". This opinion was supported by our in situ observations. We saw our participants sending links to videos (not their videos) in e-mails targeted at trusted people, as we discuss in 5 . This could have been their strategy for overcoming privacy issues. Indeed, other user groups have developed their own ways of making videos private in YouTube, as in (Lange, 2008), reviewed in 2. Thus, a perceived lack of benefit seems to be the key reason why our participants did not upload videos, and this suggests that privacy concerns raised in focus groups are much better understood if they are combined with in situ observations of technology use over an extended period of time. The importance of perception of benefit also resonates with (Ryu, Kim and Lee, 2009), despite cultural differences, which, in this case, seem to be minor.

\subsection{Types of video-content consumption}

The participants who used YouTube more frequently, did so mainly to improve skills, "I'm watching a series of videos 'cause I want to improve my golf skills. I was a bit sceptical at the beginning, but they're very good, come over and look at that, please", and to learn more about their hobbies or personal interests, "I always want to do things at home on my own, cutting corners you know, and this video is showing me how to repair the roof of a garage. It seems to be dead easy" The rest of the participants used it for fun and socialisation. The following extract shows an informal conversation between the first two authors

\footnotetext{
${ }^{8}$ Our observations and conversations indicated that all our participants had videos. They recorded videos of holidays or get-togethers with their camcorders. Their children also passed videos (e.g. of weddings) on to them in DVDs.
} 
and two participants, who were smiling and catching the attention of the other participants in a session:

[Author A]: What are you both up to? You're very noisy today and distracting the others!

[Author B]: Yes, what are you laughing at? Come on, show us!

[DUC_1]: You should come over and look at this video. It's very funny. You see? This is hilarious, and it's great fun $(\ldots)$

[DUC_2]: OK, we took our break, so now all of you back to work (smiling!)

The type of video content that our participants watch is therefore meaningful for them, providing them with a number of positive experiences (e.g. learning, socialising), as they fulfil important needs (Hassenzahl, 2010: 29]. The videos watched are not especially targeted at older people, unlike online content consumption by children, who search for child-related information categories (Torres and Weber, 2011).

\subsection{Content searching strategies}

Searching for videos in YouTube was not a common activity amongst our participants, as they mostly clicked on links embedded in their e-mails to watch videos. Only the most regular users of YouTube, and, very occasionally, the rest of participants, while talking with others or just afterwards, did use the search bar ${ }^{9}$. Most of them (20) did not look at the screen while writing the query, failing to make use of query suggestions or corrections, because, as summarised in this exemplary comment, "I need to focus on the keyboard to type in correctly what I am looking for". Their queries were also much closer to grammatically correct sentences (e.g. Ballesteros playing the <name of golf event> in <year> in Scotland) than to a list of keywords. These two search patterns (i.e. not looking at the screen while writing and using sentences) have also been found with children (Torres and Weber, 2011). However, the life experience of older people is likely to account for our results, and we plan to explore this issue further in future work, as discussed in 7.

\footnotetext{
${ }^{9}$ None of the participants used the list of categories, because they either capitalised on already learned searching strategies, "I search here as I search in Google, writing", or perceived it to be difficult, "Clicking on items? Er...how do I know where I need to click? I know what I'm looking for; I know the name of the opera singer, so I typed it in here, and that's all'.
}

\section{SOCIAL SHARING PRACTICES}

\subsection{YouTube comments are seldom read, made in person, and/or written in e-mails}

We observed that none of the participants read YouTube comments related to videos, and they reported doing so because the video was far more important for them than the comments. While a participant was watching with great attention a video about golf, namely, how to improve his swing, with his headset on, we asked them if he had read the comments below the video, to which he answered: "The video is the important thing, it's what I want to watch". Participants also pointed out that comments had a lot of offensive language and were not related to the content of the video. After having watched a song video, which had been showcased on TV the day before, a participant came to us and pointed out that: "There is a lot of crap here. You see? All these comments are a disgrace. This has nothing to do with the video! (annoyed)". These opinions are similar to the ones registered in (Lehtinen et al, 2009). However, they did not prevent our participants from using YouTube, as one can gather from opinions expressed in interviews, which are much better understood if situated in a context of extended observations of everyday ICT use.

Participants commented on videos in face-to-face conversations, "We're talking about the video of the man playing the guitar and singing in a local accent. He knows that accent, impressive!", and in e-mails to members of their social circles, mainly their sons and daughters, and friends, as illustrated in the following scenario. A participant had received an e-mail from a friend with a link to a YouTube video about advances in computing technology, and while she was watching it, she decided to send the video to her son, "Look, I'm sending this e-mail to my son, saying that this video might be interesting for his research. He is doing a $P h D$, you know? Serious stuff'. These results reinforce that intergenerational communication can occur in YouTube, as in (Harley and Fitzpatrick, 2009), and also show that this communication can be mediated and encouraged by it, with different strategies. The results also show that intragenerational communication occurs too.

We did not observe our participants writing comments in YouTube, and they reported that they would write comments "only if the video was exceptionally good", or whether their comments would be useful for other people, "If l've something constructive and useful to say, then yes". Their minimal participation in writing comments concurs with the trend suggested by data mining analyses reviewed in 2.2. Our results also show their reasons for doing so, and how their commenting 
occurs in practice, details not accessible through data mining techniques.

\subsection{Their ratings are conversations within their social circles, instead of clicks on 'thumbs up or down'}

Whereas it is often assumed that the more views or likes (i.e. thumbs up) a video has, the more likely people are going to watch it, none of our participants watched videos according to these popularity rankings. Rather, the person who recommended a video largely determined the viewing of it, and this recommendation was made in e-mails and in face-to-face conversations, never in comments on YouTube, "Who rated this video? I mean, if this video has been rated by teenagers, or let's say... people I don't know, they might be keen on things I'm not, you know what I mean, do you? Meaningful activities and details of how they are conducted are part of the user experience model suggested by (Hassenzahl, 2010: 44), namely corresponding to the "what-do goals" and "howmotor goals" of that model, together with the "whybe goal", addressed in 4.1. We discuss in 6 how these three elements help us improve older people's experiences with YouTube.

\subsection{Sharing is done by using their own, previously learned, strategies}

Rather than using the Sharing option available for registered YouTube users, all our participants used their e-mails to share videos with their close friends and relatives, involving strategies such as those illustrated in the following exemplary dialog between two participants and the main author:

\section{[Author A]: This video is great. Can you share it with me?}

[DUC_3]: Oh, aye, sure. Let me copy the address at the top...

[Author A]: Oh, I see, have you spotted the Share button here?

[DUC 4]: Yes, we were discussing that before. I clicked on it, I got the message of signing in. Too much bother. We do it in our own way

[Author A]: Which is?

[DUC_A]: Copy, then paste it into my gmail, and send. I do this copy-and-paste for other things, so it's easier for us to do it that way - we remember how to do it!

While privacy concerns might account for their unwillingness to sign up in YouTube, it is worth noting the 'easier...remember' part of the last sentence, which suggests that our participants rely on already known strategies, and this reinforces the importance of cognition over other factors, such as vision or manual dexterity, as a key factor in their interactions with ICT, which has been highlighted with a different cohort of older people too (Sayago and Blat, 2009), and shows that "older people deciding when and how to use Computer-Mediated Communication tools" (Sayago, Sloan and Blat, 2011: 551) happens in YouTube too, contradicting stereotyped views of older people making a very poor (or not intelligent) use of these technologies.

\section{DISCUSSION}

We discuss the topics addressed and main results obtained in 6.1, and some implications for design in 6.2. Afterwards, we situate our results in the context of user experience (UX) in 6.3, and discuss the methodology in 6.4.

\subsection{On the topics addressed and results}

We aimed to understand how our participants use YouTube and conduct social sharing practices while using it in out-of-laboratory conditions. We have shown that they use YouTube occasionally, mostly for watching videos that are meaningful to them and/or suggested by people they know very well. They do not upload their videos because they do not perceive any benefit in doing so, and because this content is personal, which is consistent with whom and how they conduct social sharing practices. Commenting, sharing and rating involve members of their social circles. Thus, comments written by unknown people are mostly overlooked, and socially popular videos are not watched. Other reasons for this are inappropriate language or content. Our participants conduct social sharing practices in face-to-face conversations and/or e-mails, which provide them with a personal and trustworthy context of interand intra-generational communication. They adopt strategies with which they are familiar for carrying out social sharing practices, and for searching videos too, as doing so helps them reduce cognitive load, which is paramount in their use of YouTube and ICT, in general. We have also discussed similarities and differences with other groups of SNS users.

The results outlined above have situated topics addressed by previous papers - negative concerns about SNS (Lehtinen et al, 2009; Gibson et al, 2010), intergenerational communication (Harley and Fitzpatrick, 2009), potential interest in video user-generated content (Ryu, Kim and Lee, 2009), and structure of social networks (Pfeil, Arjan and Zaphiris, 2009) - in a context of everyday YouTube use. The results have also addressed other important issues; namely, social sharing practices, searching strategies and interaction issues. Thus, our results provide a more complete picture of older 
people and their SNS use than that given by previous research.

\subsection{Some implications for design and research}

The findings can be used to draw a number of implications for supporting and enriching the quality of older people's interactions with YouTube. We discuss them within the context of whether a YouTube for older people is an interesting idea.

\subsubsection{A YouTube designed for older people?}

Whilst much of previous $\mathrm{HCl}$ research with older people has focused on designing special technologies for them, the results of a 3-year ethnographical study of Computer-Mediated Communication (CMC) tools use by 388 older people in Barcelona (Spain) (Sayago, Sloan and Blat, 2011), showed that special e-mail or videochat systems for them is not a good idea, due to the rich use this group of older people make of these tools. For instance, they avoid using technologies that foster social exclusion, e.g. joysticks for sending e-mails. Also, and over time, they explore what they can do with CMC tools. Thus, oversimplified ones that limit what they can do with them do not support this use.

So, is a YouTube for older people a bad idea, then? Our results have shown that our participants are occasional users of YouTube. The results have also shown that their participation in it is fairly passive, i.e. they search for videos and watch them, do not upload videos and do not write comments about videos in YouTube. We have not detected changes in this type of use over an 18month period. By contrast, they are much more active and frequent users of e-mail systems, as we have shown in how they use it for commenting, sharing and searching videos, and in their everyday communication, in both Barcelona (Sayago and Blat, 2010) and the DUC ${ }^{10}$. Thus, whereas an email tool that limits what older people can do with it, or makes them feel different, contradicts their use of it, a version of YouTube which enables older people to access meaningful video content for them by supporting better how they actually use this SNS (e.g. from time to time; and some key functions, at least for other user groups, e.g. uploading videos, are never used), might improve their interactions with it. We discuss this idea in more detail in 6.2.2, 6.2.3 and 6.2.4.

\subsubsection{Support cognition (mostly, in the wild)}

\footnotetext{
${ }^{10}$ Our observations and conversations indicated that all the participants had an e-mail account and checked their e-mails when they were in the DUC.
}

Although age-related changes in vision, manual dexterity and hearing impact on the interactions of older people with ICT, cognition stands out in our results. We have shown how, for instance, our participants prefer to write sentences rather than clicking on categories, which require an extra cognitive effort. For sharing videos, they capitalise on already learned strategies; new ones suggested by YouTube do not fit in with how they use it, and learning them would add extra cognitive load.

Designing for minimizing cognitive load is therefore very important, and our results suggest that doing so requires, in addition to controlled or laboratory studies, which is the most dominant approach in $\mathrm{HCl}$ research with older people (Sayago and Blat, 2009), adopting a cognition in the wild approach, since we see the results discussed above when "situating cognition in its natural habitat (..) undertaken in social settings using various tools" (Hutchings, 1995: xiii). A YouTube designed for older people without considering cognition in the wild would not be enough to reduce cognitive load over an extended period of time.

\subsubsection{Support reciprocity}

Our results show that our participants (want to) give something in return while commenting and sharing videos. For instance, we have shown that they receive e-mails from their social circles with links to, and comments about videos, and they reciprocate with e-mails regarding other videos they consider can be useful for them. We have also pointed out that our participants would write comments online if these were useful for somebody. These results are reminiscent of the "support reciprocity" suggested in (Lindley, Harper and Sellen, 2009:1699), and also found in CMC tools use (Sayago, Sloan and Blat, 2011), but might not be supported enough in YouTube. Re-thinking ratings of comments and videos in terms of usefulness to people, and even better, to their social circles, 'This is useful for your children', going beyond likes or dislikes, which do not impact on the content our participants interact with, as we have shown, might contribute to reinforce this aspect. Rather than a special YouTube, simpler ways of reciprocating, which do not increase cognitive load, might be a better idea.

\subsubsection{Would a 'family' channel foster video-content creation?}

Our participants do not upload their videos to YouTube, so a 'family channel' could encourage them to create or share video-content. However, other studies have explored this type of channel, with different technologies and groups of older people, and fairly similar types of participation have been reported- i.e. content consumption, not 
generation. For instance, ePortrait is an ambient display which shows to older people photos uploaded by their relatives - not by them - to SNS (Cornejo, Favela and Tentori, 2010). Family Portals is a video conferencing system for connecting multiple families, but grandparents "peeped, as he called it, into FP to see the remote families but never interacted", whereas the other members of the family, such as sisters and daughters, made a more active use of it (Judge et al, 2011:1210). Thus, reinforcing the strategies older people adopt for creating or sharing content, such as sending a link to a video in e-mails in the case of our participants, and considering carefully the perception of usefulness, as in the Village, a 3D Virtual community in GreyPath - a virtual community of older Australian people - wherein older people "can discuss matters of importance to themselves (...) in a way that may not be available otherwise" ${ }^{11}$ (Lepa and Tatnall, 2002: 101), can help us support, enrich and foster creation of valuable online content by older people.

\subsection{On UX with older people}

Our results can also be discussed in terms of UX with older people, who seem to have been excluded from it ${ }^{12}$.

\subsubsection{Elements of the first and second $\mathrm{HCl}$ waves}

Instrumental or task-related aspects are part of UX and of our findings. A noteworthy example is the importance of the cognitive factor in sharing strategies, replacing clicking on the 'YouTube share' button with 'sending an e-mail with the link to the video'. This task oriented-view, which corresponds to the "how" of interactions (Hassenzahl, 2010:13), is unlikely to be perceived in laboratory conditions, which are characteristic of the first wave or generation of $\mathrm{HCl}$ research. We see them emerging in a social context of ICT use, which is the hallmark of the second wave of $\mathrm{HCl}$ (Bødker, 2006). Much of $\mathrm{HCl}$ research with older people has taken place in laboratory conditions, as we have already indicated, however.

\footnotetext{
11 This perception of usefulness is also supported by our observations and conversations with the participants regarding the Ning website, a social network only for DUC members. Their participation in this SNS was very low, led by the manager and with the contribution of a handful of participants. When asked, participants reported a lack of perception of benefit, as in "I've my e-mail to talk to the folks here, and also meet them every week. Why do I need to use the Ning?"

${ }^{12}$ We analysed the 51 publications used in the 2011 review of UX research (Bargas-avila and Hornbaek, 2011) in terms of including older people $(60+)$ in their analyses, and none of them did so.
}

\subsubsection{Elements of the third or current wave}

Our results also contain elements of the "beyond the instrumental" (Hassenzahl, Tractinsky and Taylor, 2006: 92), which are key in the turn to experiences or third wave of $\mathrm{HCl}$. For instance, using YouTube for learning, fun and socialisation; watching videos that are meaningful and provide positive experiences; and a trusted context of communication in face-to-face or e-mail conversations, wherein social sharing practices are conducted, provide subjective and situated meaning to the instrumental aspects. They also address the "what" and "why" of interactions (Hassenzahl, 2010:13), providing a fairly holistic (for instance, addressing motivations, needs, steps to conduct tasks, social relationships and human factors $)^{13}$ view of the interactions of our participants with YouTube.

\subsubsection{UX and / with older people}

Within this holistic view, social aspects and the strengths of older people as ICT users stand out, suggesting that co-experiences (Batterbee, 2003) are important, and providing a more positive portrayal of older people as ICT users than that focused on limitations and removal of them - on which a lot of $\mathrm{HCl}$ research with older people has concentrated so far (Sayago, Sloan and Blat, 2011). The way in which our results were gathered, focusing on actual interactions and not on remembered ones, might also contribute to discussions on methods for gathering user experiences (Kujala et al, 2010).

\subsection{On the methodology}

Whilst classical ethnography is very scant in $\mathrm{HCl}$ as a whole and with older people (Sayago, Sloan and Blat, 2011), and in UX too (Bargas-avila and Hornbaek, 2011: 2693), the results discussed above show that our study has helped us address a number of aspects regarding older people and SNS together, and engage in a discussion on UX with them.

We do not claim that other ethnographical approaches, e.g. reduced forms of ethnography developed for $\mathrm{HCl}$ and usually conducted in shortterm periods of time (Randall, Harper and Rouncefield, 2007) might have yielded interesting results. Nor do we claim that our findings can be generalised to other groups of older people. Addressing these two main limitations warrants more research, probably ethnographical. However, the way in which we have gathered, analysed and

\footnotetext{
13 In terms of (Hassenzahl, 2010: 29), “ The distinction between be-goals $(\ldots)$ do-goals $(\ldots)$ and motor-goals $(\ldots)$ is a valuable conceptual tool to address the different levels of interacting with technology".
} 
presented the results ${ }^{14}$, and the group of older people with whom we conducted our long-term study, has allowed us to understand much better older people's YouTube use and social sharing practices. Some of our results, such as the importance of cognition, reciprocating, and meaningful use resonate with those achieved in the ethnographical study in Barcelona, with a different group of older people and technologies.

\section{CONCLUSIONS AND FUTURE WORK}

In this paper, we have discussed the everyday use of YouTube and social sharing practices by a group of older people motivated to use and learn ICT over an extended period of time.

We considered that older people's social sharing practices, within a context of real-life use of YouTube, had to be much better understood, and that this could be done by adopting a traditional, face-to-face ethnographical approach. The results confirm it.

We have shown that their use of YouTube is occasional, and mostly motivated by face-to-face or online conversations in e-mails. They watch videos that are meaningful to them and do not upload videos because they do not perceive the benefit of doing so. We have also discussed their strategies for searching videos, which are aimed at minimizing cognitive load. Regarding social sharing practices, we have shown that online comments on YouTube are seldom read nor made, but are instead targeted at key members of their social circles in $\mathrm{f} 2 \mathrm{f}$ interaction and/or in e-mails. Their way of rating videos is to talk to their friends and relatives, online and offline, and their sharing capitalizes on previously learned strategies, such as copy-and-paste. These results resonate, challenge, deepen and widen considerably previous research.

We plan to take this work further in two very different contexts. We plan to explore the role of SNS in older people's digital game play in the WorthPlay project ${ }^{15}$. This research should help us understand much better instrumental and noninstrumental aspects of SNS use and of conducting

\footnotetext{
14 "Ethnography is about telling a credible, rigorous and authentic story" (Fetterman, 2010:1). To this end, we have carefully (i) selected fieldnote extracts that are representative of what we observed and our participants reported; (ii) combined integrative and excerpt strategies [9] to weave better together extracts, results and their interpretation; (iii) triangulated in situ observations with conversations and interviews over a long period of time, and (iv) distinguished thoroughly between 'we observed' and 'they reported' to clarify the source of the results.

${ }^{15} \mathrm{http}: / /$ gti.upf.edu/worthplaying/
}

social sharing practices in them. We also aim to examine older people's SNS use in a context of independent living, supported by geo-enabled ICT, in the Life 2.0 project $^{16}$. This research should help us get a deeper insight into, for instance, privacy, video-content creation and consumption. In both research activities, we will conduct face-to-face and also online ethnography, and combine these activities with more quantitative ones, all of which will (should) help us to better understand the ethnographical method and SNS use.

\section{ACKNOWLEDGMENTS}

We are indebted to the awfy braw participants of the Dundee User Centre. They have made us feel, and become, the 'perfect stranger', and also allowed us to share their experiences with YouTube (and ICT, in general) with the research community. We also thank our team, David Sloan, Valeria Righi, Andrea Rosales, Susan Ferreira and Mireia Fernández. We acknowledge the support from the Commission for Universities and Research of the Ministry of Innovation, Universities and Enterprise of the Autonomous Government of Catalonia and the European Union.

\section{REFERENCES}

Bargas-avila, J., Hornbæk, K. (2011) Old Wine in New Bottles or Novel Challenges? A Critical Analysis of Empirical Studies of User Experience. ACM-CHI, Vancouver, BC, Canada, May 7-12, pp. 2689-2698.

Battarbee, K. (2003) Defining co-experience. International conference on Designing pleasurable products and interfaces - DPPI, Pittsburgh, Pennsylvania, June 23-26, pp. 109-113.

Bødker, S. (2006) When Second Wave $\mathrm{HCl}$ meets Third Wave Challenges. NordiCHI, location, date, Oslo, Norway, 14-18 October, pp. 14-18.

Boyd, D., Ellison, N. (2008) Social Network Sites: Definition, History and Scholarship. Journal of Computer-Mediated Communication, 13, pp. 210230.

Burguess, J., Green, J. (2011) YouTube. Online Video and Participatory Culture. Polity, Cambridge, USA.

Cha, M., Kwak, H., Rodriguez, P., Ahn, Y., Moon, S. (2007) I Tube, You Tube, Everybody Tubes: Analyzing the World's Largest User Generated Content Video System. IMC, San Diego, California, October 24-26, pp. 1-13.

Charmaz, K., Mitchell, R.G. (2007) Grounded theory in ethnography. In: Atkinson, P., Coffey, A., Delamont, S., Lofland, J., Lofland, L. (Eds.), Handbook of Ethnography. SAGE Publications, London, pp. 160-175.

\footnotetext{
${ }^{16} \mathrm{http}: / / w w w . l i f e 2$ project.eu/
} 
Cornejo, R., Favela, J., Tentori, M. (2010) Ambient Displays for Integrating Older Adults into Social Networking Sites. CRIWG, Maastricht, The Netherlands, pp. 321-336.

Emerson, R., Fretz, R., Shaw, L. (1995) Writing Ethnographic Fieldnotes. The University of Chicago, Chicago (USA)

Fetterman, D (2010) Ethnography. Step-by-Step. SAGE Publications, London.

Forbes, P., Gibson, L., Hanson, V., Gregor, P., Newell, A. (2009) Dundee user centre: a space where older people and technology meet. Proceedings of the 11th international ACM SIGACCESS conference on Computers and accessibility, Pittsburgh, Pennsylvania, USA, pp. 231-232

Gibson, L., Moncur, W., Forbes, P., Arnott, J., Martin, C. (2010) Designing Social Networking Sites for Older Adults. BSC $\mathrm{HCl}$ 2010, Dundee, Scotland, United Kingdom, 186-194.

Harley, D., Fitzpatrick, G. (2009) Creating a conversational context through video blogging: $A$ case study of Geriatric1927. Computers in Human Behavior, 25:3, pp. 679-689.

Hassenzahl, M. (2010) Experience Design. Technology for All the Right Reasons. Morgan \& Claypool Publishers, USA.

Hassenzahl, M., Tractinsky, N., Taylor, P. (2006) User experience - a research agenda. Behaviour \& Information Technology, 25:2, 91-97.

Hutchings, E. (1995) Cognition in the Wild. Cambridge, The MIT Press, Massachusetts.

Judge, T., Neustaedter, C., Harrison, S., Blose, A. (2011) Family Portals: Connecting Families Through a Multifamily Media Space. ACM-CHI, Vancouver, BC, Canada, May 7-12, pp. 12051214.

Kujala, S., Roto, V., Väänänen-Vainio-Mattila, K., Karapanos, E., Sinnelä, S. (2011) UX Curve: A method for evaluating long-term user experience. Interacting with Computers, 23:5, pp. 473-483.

Kwasny, M., Caine, K., Rogers, W., Fisk, A. (2008) Privacy and Technology: Folk Definitions and Perspectives. ACM-CHI - Works in Progress, Florence, Italy, April 5-10, pp. 3291-3296.

Lange, P. (2008) Publicly Private and Privately Public: Social Networking on YouTube. Journal of Computer-Mediated Communication, 13, pp. 361380.

Lehtinen, V., Näasäanen, J., Sarvas, R. (2009) A Little Silly and Empty-Headed ' - Older Adults' Understandings of Social Networking Sites, $\mathrm{HCl}$ 2009 - People and Computers XXIII, Cambridge, United Kingdom, pp. 45-54.

Lepa, J., Tatnall, A. (2002) The GreyPath web portal - reaching out to virtual communities of older people in regional areas. ITIRA Conference, Rockhampton, Queensland, Australia, 26-29 August, pp. 97-103.

Lindley, S., Harper, R., Sellen, A. (2009) Desiring to be in touch in a changing communications landscape: attitudes of older adults. ACM-CHI, Boston, MA, April 4-9, pp. 1693-1702.

Pfeil, U., Arjan, R., Zaphiris, P. (2009) Age differences in online social networking - A study of user profiles and the social capital divide among teenagers and older users in MySpace. Computers in Human Behavior, 25:3, pp. 643-654.

Poblete, B., Garcia, R., Mendoza, M., Jaimes, A. (2011) Do All Birds Tweet the Same? Characterizing Twitter Around the World Categories and Subject Descriptors. CIKM, Glasgow, Scotland, October 24-28, pp. 1025-1030. Randall, D., Harper, R., Rouncefield, M. (2007) Fieldwork for Design. Theory and Practice. Springer, London.

Ryu, M., Kim, S., Lee, E. (2009) Understanding the factors affecting online elderly user's participation in video UCC services. Computers in Human Behavior, 25:3, pp. 619-632.

Sayago, S., Blat, J. (2009) About the relevance of accessibility barriers in the everyday interactions of older people with the web, International Crossdisciplinary Conference on Web Accessibility (W4A-ACM), April 20-21, Madrid (Spain), pp. 104113.

Sayago, S., Blat, J. (2010) Telling the story of older people e-mailing: an ethnographical study, International Journal of Human-Computer Studies, 68, pp. $105-120$

Sayago, S., Sloan, D., Blat, J. (2011) Everyday use of computer-mediated communication tools and its evolution over time: an ethnographical study with older people. Interacting with Computers, 23(5), pp. 543-554.

Siersdorfer, S., Chelaru, S., Nejdl, W., San Pedro, J. (2010) How Useful are Your Comments? Analyzing and Predicting YouTube Comments and Comment Ratings. WWW 2010, location, date, Raleigh, North Carolina, USA, April 26-30, pp. 891900.

Torres, S., Weber, I. (2011) What and How Children Search on the Web. CIKM, Glasgow, Scotland, October 24-28, pp. 393-402.

Venkatesh, V., Morris, M., Davis, G., Davis, F. (2003) USER ACCEPTANCE OF INFORMATION TECHNOLOGY : TOWARD A UNIFIED VIEW. MIS Quarterly, 27:3, pp. 425-478.

Wilson, C., Boe, B., Sala, A., Puttaswamy, K., Zhao, B. (2009) User Interactions in Social Networks and their Implications. EuroSys, Nuremberg, Germany, April 1-3, pp. 1-14. 